\title{
EFFICIENCY ASSESSMENT OF WAVELET TRANSFORMS AND WAVELETS FOR DAMAGE LOCALIZATION IN BEAMS USING SHEAROGRAPHY
}

\author{
Aleksander KROWORZ ${ }^{1}$, Andrzej KATUNIN ${ }^{1}$, Hernâni LOPES ${ }^{2}$, José ARAÚJO DOS SANTOS ${ }^{3}$ \\ ${ }^{1}$ Institute of Fundamentals of Machinery Design, Silesian University of Technology, Konarskiego 18A, \\ 44-100 Gliwice, Poland, e-mail: andrzej.katunin@ @olsl.pl \\ ${ }^{2}$ Department of Mechanical Engineering, ISEP, Polytechnic of Porto, R. Dr. António Bernardino \\ de Almeida 431, 4249-015 Porto, Portugal, hml@isep.ipp.pt \\ ${ }^{3}$ IDMEC, Instituto Superior Técnico, Universidade de Lisboa, Lisboa, Portugal, Av. Rovisco Pais 1, \\ 1049-001 Lisbon, Portugal, viriato@ tecnico.ulisboa.pt
}

\begin{abstract}
Non-destructive testing of engineering structures and elements in operation is one of the crucial steps in recently introduced design philosophies: damage tolerance and condition-based maintenance. Therefore, it is important to provide effective non-destructive testing methods, which are able to detect and identify a possible damage in early stage of its development. One effective testing method, which still gains its popularity in various industrial applications, is shearography. Although, shearography is sensitive to various types of structural damage and flaws, this sensitivity can be significantly improved by applying advanced post-processing algorithms to raw data obtained from measurements. An excellent candidate for such an improvement is the wavelet analysis, due to its very high sensitivity to smallest signal disturbances. This study presents results of comparative analysis of various wavelet transforms and various wavelets in order to analyse their sensitivity to damage. The improvement in damage detectability is verified using experimental data.
\end{abstract}

Keywords: non-destructive testing, shearography, modal rotation, wavelet transform

\section{OCENA EFEKTYWNOŚCI TRANSFORMACJI FALKOWYCH I FALEK W ZASTOSOWANIU DO LOKALIZACJI USZKODZEŃ W BELKACH Z WYKORZYSTANIEM SHEAROGRAFII}

\section{Streszczenie}

Badania nieniszczące inżynierskich struktur i elementów będących w eksploatacji są jednym z najważniejszych kroków w obecnie zapoczątkowanych filozofii projektowania: tolerancji uszkodzenia oraz eksploatacji na podstawie stanu. Dlatego ważnym jest wykorzystanie efektywnych metod badań nieniszczących, które są zdolne do detekcji i identyfikacji możliwego uszkodzenia we wczesnej fazie jego rozwoju. Jedną $\mathrm{z}$ efektywnych metod badawczych, która wciąż zyskuje na popularności w różnych zastosowaniach przemysłowych, jest shearografia. Mimo że shearografia jest wrażliwa na różne rodzaje uszkodzeń i wad w strukturach, jej wrażliwość może być znacząco ulepszona poprzez zastosowanie zaawansowanych algorytmów przetwarzania do surowych danych wynikowych otrzymanych z pomiarów. Doskonałym kandydatem dla takiego polepszenia jest analiza falkowa ze względu na jej bardzo dużą wrażliwość na najmniejsze zaburzenia w sygnale. Niniejsza praca przedstawia wyniki analizy porównawczej różnych transformacji falkowych oraz różnych falek w celu analizy ich wrażliwości na uszkodzenia. Polepszenie wykrywalności uszkodzeń zostało zweryfikowane z wykorzystaniem danych eksperymentalnych.

Słowa kluczowe: badania nieniszczące, shearografia, rotacja modalna, transformacja falkowa

\section{INTRODUCTION}

The main assumption of non-destructive testing (NDT) of structures is the examination of materials, components or systems that serve to characterize or find defects without damaging the tested object or unintentional alteration of its original features. For instance, in aircraft design methodology, the damage tolerance philosophy states that in the event of failure during operation, the aircraft should retain its property and perform its task until it is repaired or replaced, if the damage or the repair costs are too high [1]. Similar attitudes can be observed in other industries, for example, in machine industry, automotive industry, and in the industries of wind and nuclear energies.

This philosophical approach is reflected in the condition-based maintenance (CBM), which aims to monitor the actual status of assets in order to be able to decide what maintenance works should be performed [2]. Another goal motivating this approach is to reduce maintenance costs, to improve operational safety, and to reduce the amount of system failures. So far, the CBM strategy 
is most commonly used in the wind energy industry, where the long life of turbine blades is achieved thanks to the implemented conservation plans, whose main purpose is to detect damage at their earliest stage of development.

In another stage, appropriate maintenance works are determined, where the replacement of the damaged element or its repair can be specified [3]. Nevertheless, the constantly growing requirements of the industry related to the quality and reliability of product cause that the standards of methods also increase. The NDT methods used so far in various branches of industry (e.g. ultrasonic, magnetic, radiographic, thermographic) are not enough to meet all imposed requirements, such as ability to scan large areas at once, robustness, unilateral access, real time results or insensitivity to accidental shifting of measuring apparatus. Due to this, the shearographic method was discovered, which has already proven its value and usefulness in industry.

Shearography, also known as speckle pattern shearing interferometry, is an alternative to electronic speckle pattern interferometry (ESPI) and belongs to the family of interferometric methods. The method was developed in the early 1970s to solve several limitations related to interferometric holography [4, 5]. Unlike other NDT methods, it is non-contact, full field, robust, and is also able to scan large areas at once without contact and allows for static and dynamic measurements with high resolution [6]. Moreover, while holography and ESPI measure surface displacement, shearography measures the derivatives of surface displacement, which leads to yield strain and strain concentration information directly [7]. Shearography is less sensitive than ESPI to accidental displacements of the measuring system caused by vibrations or external perturbations, thus allowing the use of this method outside the controlled ambient of a laboratory [8,9]. This is one of the reasons why shearography gained acceptance from industry since its discovered. Nowadays, shearography is one of the most promising optical techniques in the field of NDT. The rubber industry already adopted shearography for evaluating tires [10]. Moreover, this method has been endorsed by the U.S. Federal Aviation Administration (FAA) as a compulsory testing and evaluation for aircraft tires [11] and by the European Aviation Safety Agency (EASA) as a reliable method of controlling composite structures [12].

Like many other NDT methods, shearography is affected by optical distortions caused by inaccurate positioning of the phase-shifting and shearing mirrors, as well as by errors related to the stability of the components of the measurement setup [13]. Moreover, a small size damage is not always localized properly. In this case, additional signal processing tools are necessary to improve efficiency. One of those tools is wavelet analysis
(WA), which has been already used as a diagnostic supporting tool for the enhancement of NDT methods [14]. Its ability to identify singularities and discontinuities in the analysed signal makes it promising for damage identification problems, which was already proven in a previous study [15].

The aim of this paper is to compare the effectiveness of various wavelet transforms (WTs) as a post-processing tool of shearographic data. The authors considered three of the most commonly applied types of WTs, namely continuous wavelet transform (CWT), discrete wavelet transform (DWT), and stationary wavelet transform (SWT). The improvement in damage detectability was observed in all applied WTs.

\section{SHEAROGRAPHY AND DAMAGE CASES}

Shearography, which the full name is speckle pattern shearing interferometry, is an interferometric measurement technique that makes use of coherent laser illumination [8]. The main assumption for introducing shearography was to overcome the limitations of its predecessors, that is holography and ESPI $[4,5]$. This goal was achieved by creating the reference beam from the same optical path of the object beam. This operation led to a simple optical system. In addition, the length of the laser's coherence was reduced. Finally, this replacement allowed for measurement of the derivatives of surface displacement, while the predecessors of the shearographic method measure surface displacement [7, 10]. The detailed description of the physical principles of shearography can be found in [16].

The tested specimen is an aluminium beam of $400 \times 40 \times 3 \mathrm{~mm}^{3}$, in which different damage scenarios were created by making slots, with depths with a maximum resolution of $5 \mu \mathrm{m}$, using a milling machine [6]. The first slot has a width of 5 $\mathrm{mm}$, and the second $3 \mathrm{~mm}$. In order to achieve a slight reduction of the bending stiffness of the beam, and checking the sensitivity of the proposed methodology, various depths of slots were chosen (see Table 1). The used experimental setup is presented in Fig. 1. A loudspeaker is used to acoustically excite the beam, which is suspended by two rubber bands. The in-plane surface of the beam is illuminated by a continuous-wave laser with a wavelength of $535 \mathrm{~nm}$ and output power of $1.3 \mathrm{~W}$. An acousto-optic modulator is used to pulse the laser and synchronize it with the beam vibration. A digital camera with a spatial resolution of 4 million points records intensity patterns, produced by the optical interferometer. In order to extract the phase of the light from the recorded intensity patterns, a temporal phase shifting is applied. The tests were performed at three different excitation levels. For more detailed information about the experimental setup and preparation, the reader is referred to [6]. 


\begin{tabular}{|c|c|c|}
\multicolumn{2}{c}{} & \multicolumn{2}{c}{ Table 1. Damage scenarios } \\
\hline $\begin{array}{c}\text { Damage } \\
\text { scenario }\end{array}$ & $\begin{array}{c}\text { Slot 1 depth } \\
{[\mathbf{m m}]}\end{array}$ & $\begin{array}{c}\text { Slot 2 depth } \\
{[\mathbf{m m}]}\end{array}$ \\
\hline 1 & 0.1 & $\mathrm{n} / \mathrm{a}$ \\
\hline 2 & 0.22 & $\mathrm{n} / \mathrm{a}$ \\
\hline 3 & 0.30 & $\mathrm{n} / \mathrm{a}$ \\
\hline 4 & 0.41 & $\mathrm{n} / \mathrm{a}$ \\
\hline 5 & 0.41 & 0.03 \\
\hline 6 & 0.41 & 0.10 \\
\hline 7 & 0.41 & 0.19 \\
\hline 8 & 0.41 & 0.30 \\
\hline
\end{tabular}
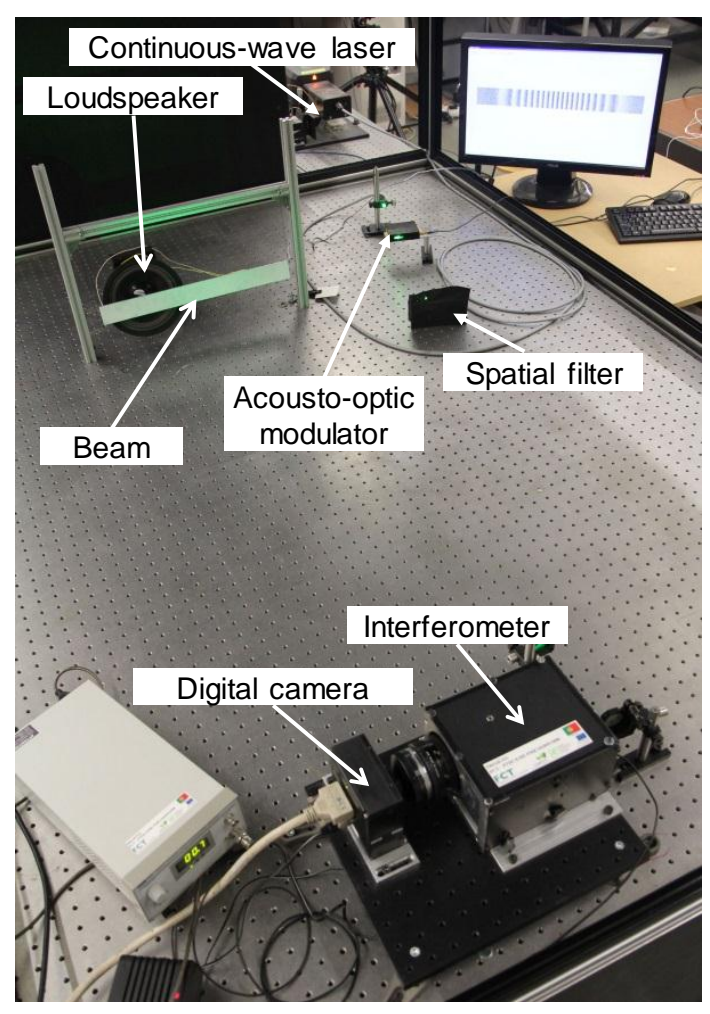

Fig. 1. Experimental setup for the measurement of the modal rotations with shearography

Shearographic measurements rely on sets of intensity patterns in the reference and deformed states. In order to obtain modal rotation fields from these intensity patterns it is necessary to perform several operations. Firstly, the reference and deformed state patterns are transformed into a phase map by phase shifting. This phase map contains noise, and thus filtering is necessary. In the present study, the sine/cosine average filter was applied, which shows effectiveness in filtering proven in the previous studies $[6,15]$. Afterwards, the resulting filtered phase map was subjected to unwrapping procedure following the Goldstein unwrapping algorithm. Finally, the modal rotation field $\partial w(x, y) / \partial x$ is obtained by applying the following equation to the unwrapped phase map $\Delta \phi(x, y)$ :

$$
\frac{\partial w(x, y)}{\partial x}=\frac{\lambda}{4 \pi \Delta x} \Delta \phi(x, y),
$$

where $\lambda$ is the wavelength of the light used to illuminate the surface and $\Delta x$ is the shearing amount. A profile is afterwards extracted from the modal rotation field, which consists in the middle values with respect to the specimen width. A diagram describing some of the steps to obtain the first bending modal rotation field and corresponding profile is presented in Fig. 2. Note that in this study four profiles, relative to the first four modal rotation fields of the beam, for each damage state, were post-processed with wavelets.

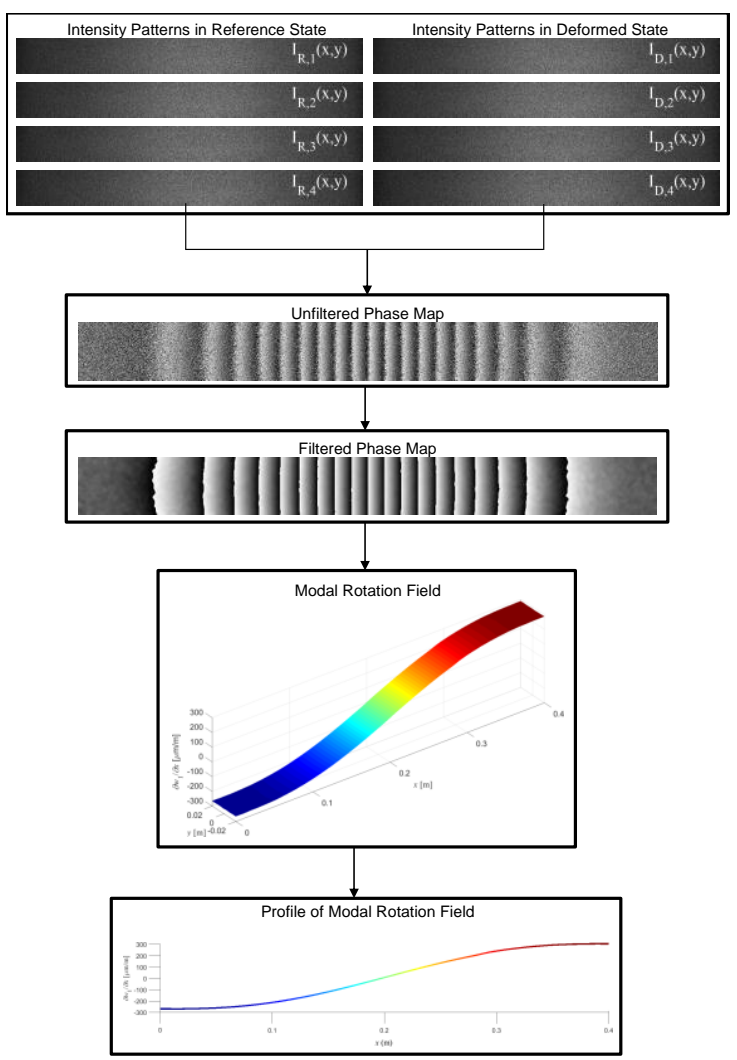

Fig. 2. Diagram for the measurement of modal rotation fields

\section{WAVELET ANALYSIS}

\subsection{Fundamentals of wavelet analysis}

A wavelet transform has numerous advantages with respect to Fourier transform or Short-Time Fourier Transform, mainly due to its multiresolution property, and the possibility of selecting a basis function. These properties make WT very sensitive to disturbances in the analysed signals. From the variety of types of WTs, three most widespread types were selected in the present study.

The CWT is the oldest wavelet transform, which can be expressed by the following relation:

$$
W f(a, b)=a^{-2} \int_{-\infty}^{\infty} f(x) \Psi\left(\frac{x-b}{a}\right) d x,
$$

where $W f(a, b)$ is a set of resulting wavelet coefficients dependent on a scale parameter $a$ and a translation parameter $b$, being $f(x)$ the analysed signal, and $\Psi((x-b) / a)$ the applied wavelet function. The operation of transform is based on the adjustment of a wavelet function, appropriately dilated at different scales, resulting in a scalogram, 
which is a kind of a time-frequency representation of a signal. CWT does not have strong restrictions to the type of wavelet function, which can be almost arbitrary. Nonetheless, an admissibility condition should be preserved:

$$
\int_{-\infty}^{\infty} \Psi(a, b) d x=0,
$$

The DWT is based on the multiresolution analysis, providing decomposition as well as stability of approximate reconstruction of functions at different resolutions. The decomposition of a signal $f(x)$ can be represented by:

$$
f(x)=\sum_{-\infty}^{\infty} f_{n}^{0} \varphi(x-n),
$$

where the translation procedure using the scaling function is denoted by $\varphi(x-n)$. The decomposition procedure can be expressed by filters, leading to sets of approximation coefficients $f_{n}^{(j)}$ and detail $d_{n}^{(j)}$ coefficients can be described by:

$$
\begin{aligned}
& f_{n}^{(j)}(x)=\sum_{l} g_{2 n-l} f_{l}^{(j-1)}, \\
& d_{n}^{(j)}(x)=\sum_{l} h_{2 n-l} f_{l}^{(j-1)},
\end{aligned}
$$

where $j$ is the decomposition level, and $h$ and $g$ are the impulse responses of the low-pass and highpass filters, respectively.

Unlike the DWT, the SWT does not contain the downsampling operation, leading to sets of approximation and detail coefficients after decomposition that have the same length as the input signal (in DWT these sets are reduced twice). This fact is the origin of the redundancy of SWT with respect to DWT, and relations (5) and (6) can be presented as follows:

$$
\begin{aligned}
& f_{n}^{(j+1)}(x)=\sum_{l} g_{2 n-l} f_{l}^{(j)} \\
& d_{n}^{(j+1)}(x)=\sum_{l} h_{2 n-l} f_{l}^{(j)}
\end{aligned}
$$

However, at the cost of redundancy, SWT provides shift invariance. The description of the mathematical details of the presented WTs can be found in [17].

\subsection{Wavelet bases and analysis parameters}

In order to test the effectiveness of the various wavelets, several assumptions were made before the beginning of the comparative study. Since DWT and SWT require (semi-, bi-) orthogonality or orthonormality of wavelet bases, the possible wavelets were limited to those having the possibility of direct comparison of resulting sets of wavelet coefficients. Moreover, because the blurring at detected disturbances in a signal increases with the increase of the wavelet order, which was proven experimentally in many studies (see e.g. [17]), the order of the wavelets considered in the present study was limited to 3 . Following these assumptions, 6 wavelets were selected (see Table 2).

\begin{tabular}{|c|c|c|}
\multicolumn{4}{|c}{ Table 2. List of selected wavelet bases } \\
\begin{tabular}{|c|c|c|}
\hline Wavelet & Symbol & Orders \\
\hline Daubechies & $d b$ & $1,2,3$ \\
\hline Symlet & sym & 2,3 \\
\hline Coiflet & coif & 2,3 \\
\hline Biorthogonal & bior & $2.2,3.5$ \\
\hline Reversed biorthogonal & rbio & $2.2,3.5$ \\
\hline Discrete Meyer & dmey & - \\
\hline
\end{tabular}
\end{tabular}

The comparative study for the selection of wavelet type and order was performed on preprocessed data of the damage scenario 4 (see Table 1), which is a case of single damage with the highest depth of the slot. The results of the performed comparative study show that $d b 2$ provided the most effective damage detection among all considered wavelet. In particular, it was observed that $d b 1$ and dmey were not effective in damage detection due to the high level of noise (see Fig. 3a), while sym3, coif 2 , coif 3 , bior 3.5 , rbio3.5 detected the damage, but the results were ambiguous, and the statement about damage presence cannot be made (see Fig. 3b). Finally, sym 2, bior 2.2, and rbio 2.2 have similar effectiveness in damage localization as $d b 2$. Nevertheless, in the case of the scenario with double damage or depth of single damage lower than $0.41 \mathrm{~mm}$, their accuracy gets much worse, contrary to $d b 2$. In order to prove the effectiveness of damage identification using $d b 2$ the analysis was performed for all considered WTs. The results of damage identification are presented in Fig. 3c-e. Note that for CWT a scale parameter $a=50$ was considered, while in the case of DWT and SWT only detail coefficients were taken into account.

Due to the presence of noise in the wavelet coefficients and in order to reduce arbitrariness in the assessment of the damage location, it was decided to introduce a measure, which allows for a unified thresholding and conclusions about damage detectability. At the first stage all the resulting sets of wavelet coefficients were analysed for whether the highest peak is located in the location of the damage, i.e. in the location of the introduced slot. If not, the damage was considered as undetected (see Fig. 4a for instance). The remaining sets were examined according to the following rule:

$$
T D=\left\{\begin{array}{l}
1 \text { if } p_{1}(d(x)) \geq 1.25 p_{2}(d(x)), \\
0 \text { if } p_{1}(d(x))<1.25 p_{2}(d(x)),
\end{array}\right.
$$

where $T D$ is the true damage detection indicator, $p_{1}(d(x))$ means the height of the peak at the damage location, and $p_{2}(d(x))$ the height of the second highest peak in the signal. The example of an undetected damage according to (9) is shown in Fig. 4b. The results of the exams using the rule in (9) are presented in tabular form in the next section. Whenever a slot is well localized, the cells in the tables show a $\checkmark$, whereas if the slot is not localized a $x$ is presented. Since we have two slots in damage scenarios 5 to 8 , the tables present two columns for these damage scenarios and each mode. 


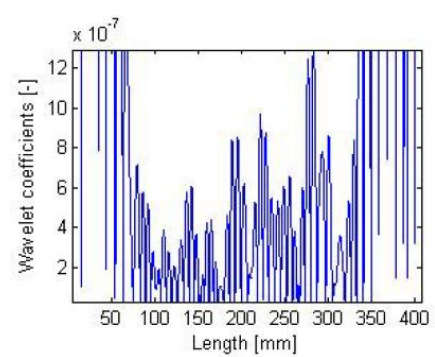

(a)

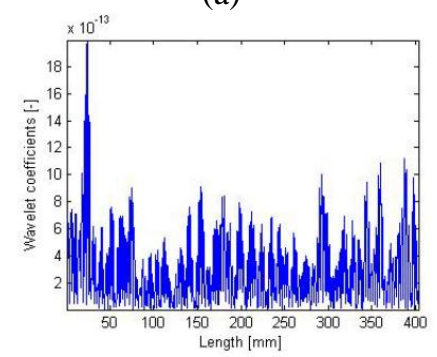

(b)

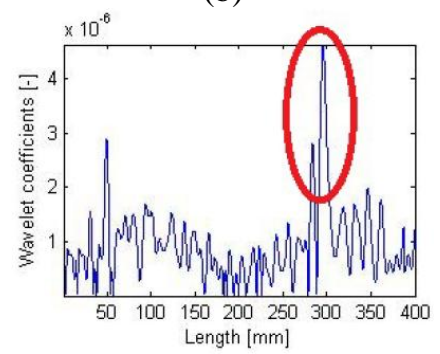

(c)

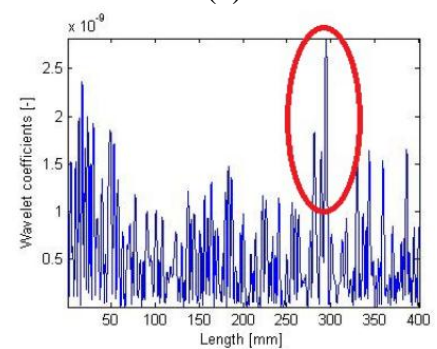

(d)

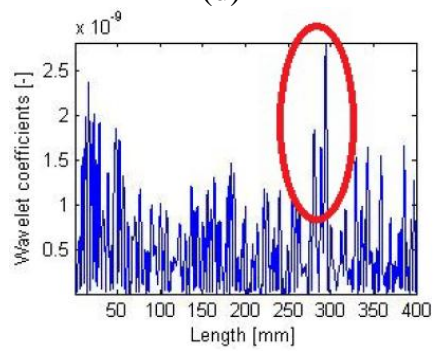

(e)

Fig. 3. Results of damage identification using CWT and a) dmey wavelet, b) bior 3.5 wavelet, c) $d b 2$ wavelet, and d) DWT, e) SWT with $d b 2$ wavelet

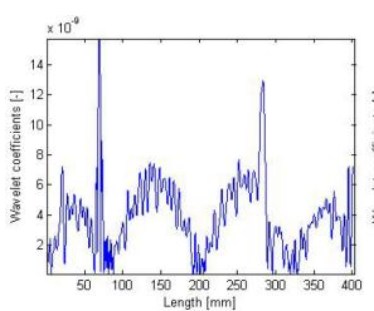

(a)

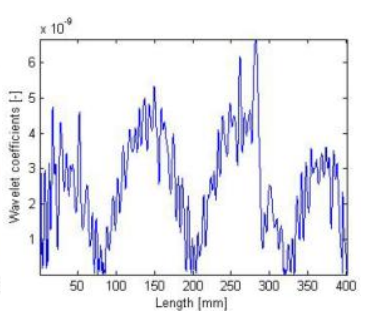

(b)
Fig. 4. Examples of damage considered as undetected according to the assumed detectability criteria

\section{RESULTS OF DAMAGE IDENTIFICATION}

Wavelet analysis has been carried out for the eight damage scenarios listed in Table 1. For each damage scenario, four bending mode shapes and three excitation levels were considered. Both factors have an influence in the damage detectability of the considered cases. The obtained results were divided into subsections, each one relative to the applied WTs. According to the results of the previous analyses, in each case the $d b 2$ wavelet was applied. In all cases, the absolute values of the wavelet coefficients are presented.

\subsection{Damage identification using CWT}

The application of CWT results in a set of vectors (in this case they are attributed to the length of the tested specimens) for corresponding values of a scale parameter $a$. From the results of a preliminary analysis it was assumed that $a=50$, since this value gives the best ratio of the peak at damage location to the noise for the considered problem. The obtained results for the eight damage scenarios are presented in Table 3. The results presented correspond to the data with the lowest excitation level.

Table 3. Results of damage identification using CWT

\begin{tabular}{|c|c|c|c|c|c|c|c|c|}
\hline $\begin{array}{c}\text { Damage } \\
\text { scenario }\end{array}$ & Mode 1 & Mode 2 & Mode 3 & Mode 4 \\
\hline 1 & \multicolumn{1}{|c|}{ x } & \multicolumn{2}{|c|}{ x } & \multicolumn{2}{|c|}{ x } & \multicolumn{2}{|c|}{ x } \\
\hline 2 & \multicolumn{1}{|c|}{$\times$} & \multicolumn{2}{|c|}{$\checkmark$} & \multicolumn{2}{|c|}{$\checkmark$} & \multicolumn{2}{|c|}{ x } \\
\hline 3 & \multicolumn{2}{|c|}{$\checkmark$} & \multicolumn{2}{|c|}{$\checkmark$} & \multicolumn{2}{|c|}{$\checkmark$} & \multicolumn{2}{|c|}{$\times$} \\
\hline 4 & \multicolumn{2}{|c|}{$\checkmark$} & \multicolumn{2}{|c|}{$\checkmark$} & \multicolumn{2}{|c|}{$\times$} \\
\hline 5 & $\checkmark$ & $x$ & $\checkmark$ & $x$ & $\checkmark$ & $x$ & $x$ & $x$ \\
\hline 6 & $\checkmark$ & $x$ & $\checkmark$ & $x$ & $\checkmark$ & $x$ & $x$ & $x$ \\
\hline 7 & $\checkmark$ & $x$ & $\checkmark$ & $x$ & $\checkmark$ & $\checkmark$ & $x$ & $x$ \\
\hline 8 & $\checkmark$ & $\checkmark$ & $\checkmark$ & $x$ & $\checkmark$ & $\checkmark$ & $x$ & $x$ \\
\hline
\end{tabular}

The obtained results show that the CWT-based algorithm allows to detect damage starting from a slot depth of $0.22 \mathrm{~mm}$ (damage scenario 2) for a single damage, and from a slot depth of $0.19 \mathrm{~mm}$ (damage scenario 7) for a double damage. Illustrative results with the CWT-based algorithm are presented in Figs. 5 and 6. Moreover, it was observed that the first three modal rotations reveal high sensitivity to damage. 


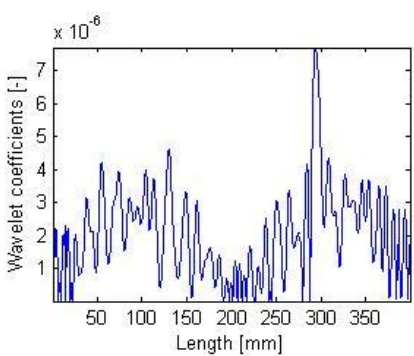

(a)

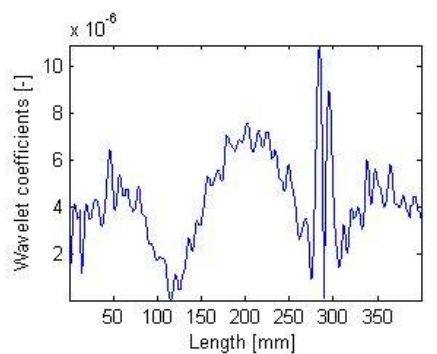

(b)

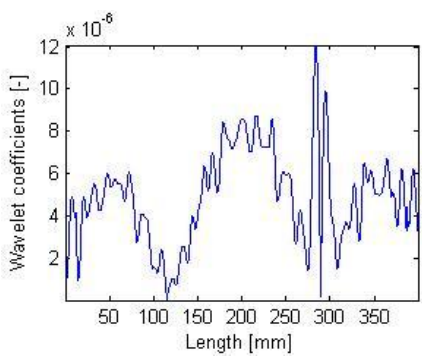

(c)

Fig. 5. Results of damage identification for damage scenario 3 obtained using CWT, for: a) first modal rotation; b) second modal rotation; c) third modal rotation

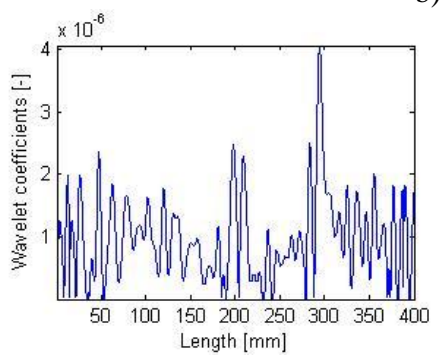

(a)

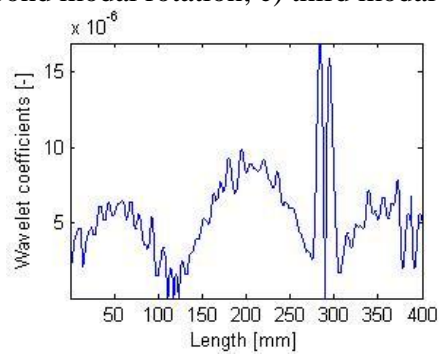

(b)

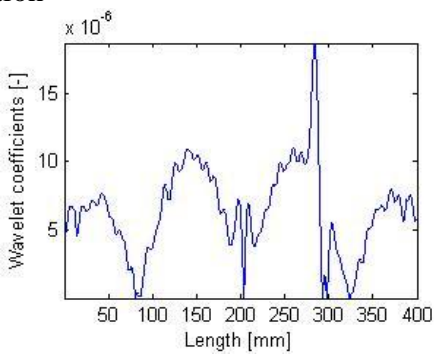

(c)

Fig. 6. Results of damage identification for damage scenario 8 obtained using CWT, for: a) first modal rotation; b) second modal rotation; c) third modal rotation

\subsection{Damage identification using DWT}

A similar analysis of damage detectability was performed using DWT. In this case a single-level decomposition of each mode shape for each damage scenario was carried out, and only sets of detail coefficients were taken into account (since these coefficients contain information about small signal disturbances, which can be considered in this case as diagnostic information). The results of the performed study are presented in Table 4.

Table 4. Results of damage identification using DWT

\begin{tabular}{|c|c|c|c|c|c|c|c|c|}
\hline $\begin{array}{l}\text { Damage } \\
\text { scenario }\end{array}$ & \multicolumn{2}{|c|}{ Mode 1} & \multicolumn{2}{|c|}{ Mode 2} & \multicolumn{2}{|c|}{ Mode 3} & \multicolumn{2}{|c|}{ Mode 4} \\
\hline 1 & \multicolumn{2}{|c|}{$x$} & \multicolumn{2}{|c|}{$x$} & \multicolumn{2}{|c|}{$x$} & \multicolumn{2}{|c|}{$x$} \\
\hline 2 & \multicolumn{2}{|c|}{$x$} & \multicolumn{2}{|c|}{$x$} & \multicolumn{2}{|c|}{$\checkmark$} & \multicolumn{2}{|c|}{$x$} \\
\hline 3 & \multicolumn{2}{|c|}{$x$} & \multicolumn{2}{|c|}{$x$} & \multicolumn{2}{|c|}{$\checkmark$} & \multicolumn{2}{|c|}{$x$} \\
\hline 4 & \multicolumn{2}{|c|}{$\checkmark$} & \multicolumn{2}{|c|}{$\checkmark$} & \multicolumn{2}{|c|}{$\checkmark$} & \multicolumn{2}{|c|}{$x$} \\
\hline 5 & $x$ & $x$ & $\checkmark$ & $x$ & $\checkmark$ & $x$ & $x$ & $x$ \\
\hline 6 & $x$ & $x$ & $\bar{\checkmark}$ & $x$ & $\checkmark$ & $x$ & $x$ & $x$ \\
\hline 7 & $x$ & $x$ & $\checkmark$ & $x$ & $\checkmark$ & $x$ & $x$ & $x$ \\
\hline 8 & $x$ & $x$ & $\checkmark$ & $x$ & $\checkmark$ & $x$ & $x$ & $x$ \\
\hline
\end{tabular}

The obtained results with DWT present a worse damage detectability, which was caused mainly by the higher level of high-frequency noise in the resulting sets of detail coefficients (see Figs. 7 and 8 for instance). The damage starts to be detected from a slot depth of $0.22 \mathrm{~mm}$ (damage scenario 2), but only for mode 3 , which was also the most sensitive to damage. The damage signature for the second slot was not detected in any scenario using the DWT-based algorithm.

\subsection{Damage identification using SWT}

The settings for the SWT-based algorithm were the same as for DWT. As previously, only absolute values of detail coefficients were considered. The obtained results are presented in Table 5. The illustrative results of damage identification are presented in Figs. 9 and 10.

Table 5. Results of damage identification using SWT

\begin{tabular}{|c|c|c|c|c|c|c|c|c|}
\hline $\begin{array}{l}\text { Damage } \\
\text { scenario }\end{array}$ & \multicolumn{2}{|c|}{ Mode 1} & \multicolumn{2}{|c|}{ Mode 2} & \multicolumn{2}{|c|}{ Mode 3} & \multicolumn{2}{|c|}{ Mode 4} \\
\hline 1 & \multicolumn{2}{|c|}{$x$} & \multicolumn{2}{|c|}{$x$} & \multicolumn{2}{|c|}{$x$} & \multicolumn{2}{|c|}{$x$} \\
\hline 2 & \multicolumn{2}{|c|}{$x$} & \multicolumn{2}{|c|}{$x$} & \multicolumn{2}{|c|}{$x$} & \multicolumn{2}{|c|}{$x$} \\
\hline 3 & \multicolumn{2}{|c|}{$x$} & \multicolumn{2}{|c|}{$\checkmark$} & \multicolumn{2}{|c|}{$\checkmark$} & \multicolumn{2}{|c|}{$x$} \\
\hline 4 & \multicolumn{2}{|c|}{$\checkmark$} & \multicolumn{2}{|c|}{$\checkmark$} & \multicolumn{2}{|c|}{$\checkmark$} & \multicolumn{2}{|c|}{$x$} \\
\hline 5 & $x$ & $x$ & $\checkmark$ & $x$ & $\checkmark$ & $x$ & $x$ & $x$ \\
\hline 6 & $x$ & $x$ & $\checkmark$ & $x$ & $\checkmark$ & $x$ & $x$ & $\bar{x}$ \\
\hline 7 & $x$ & $x$ & $\checkmark$ & $x$ & $\checkmark$ & $x$ & $x$ & $x$ \\
\hline 8 & $x$ & $x$ & $\checkmark$ & $x$ & $\checkmark$ & $x$ & $x$ & $x$ \\
\hline
\end{tabular}

As it can be observed, the results obtained using the SWT-based algorithm are very similar to those obtained using the DWT-based algorithm: the presence of high-frequency noise masks the damage signatures. The sensitivity of mode 2 and 3 is the same for SWT-based algorithm. The second slot is barely detected in the results for scenario 8 (see Fig. 10b,c), however the assumed criteria do not allow to conclude about the detection of this damage, since in the case when the presence and location of damage is unknown the conclusion about damage presence can be ambiguous. 


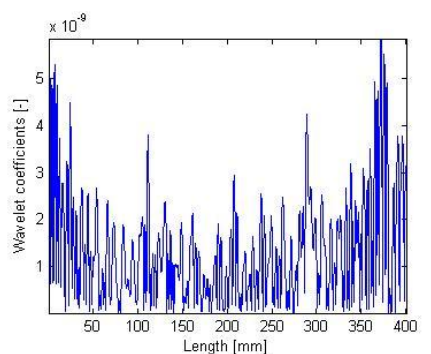

(a)

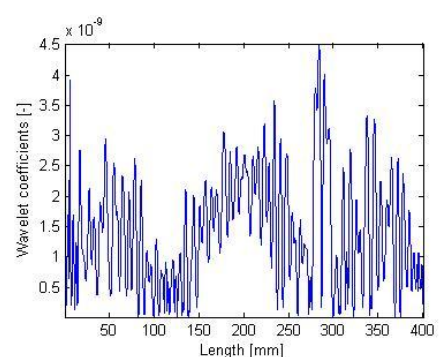

(b)

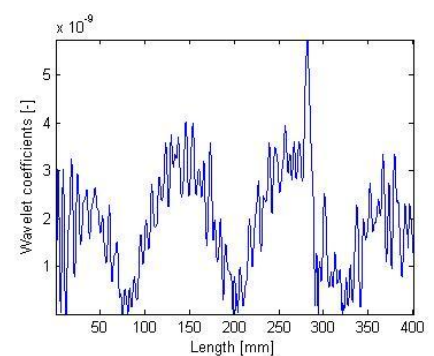

(c)

Fig. 7. Results of damage identification for damage scenario 3 obtained using DWT, for: a) first modal rotation; b) second modal rotation; c) third modal rotation

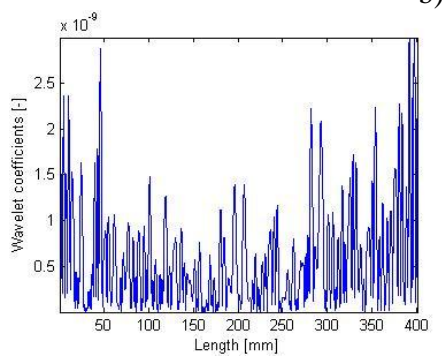

(a)

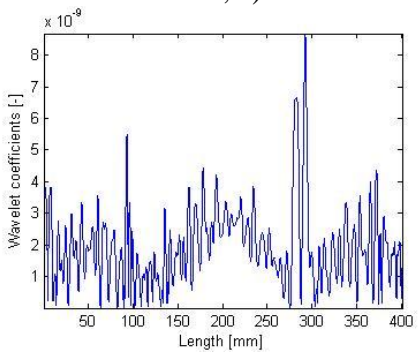

(b)

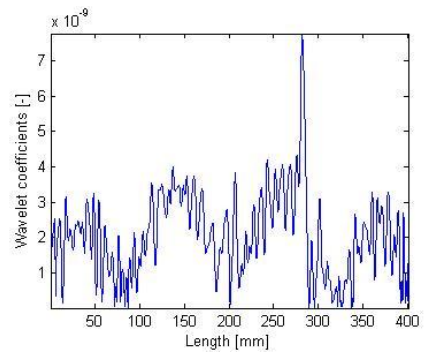

(c)

Fig. 8. Results of damage identification for damage scenario 8 obtained using DWT, for: a) first modal rotation; b) second modal rotation; c) third modal rotation

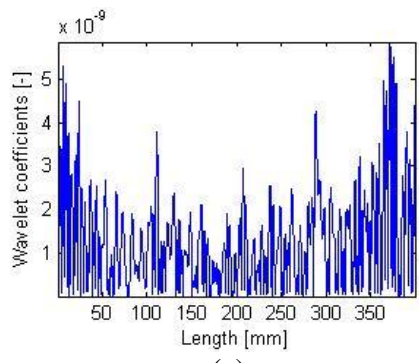

(a)

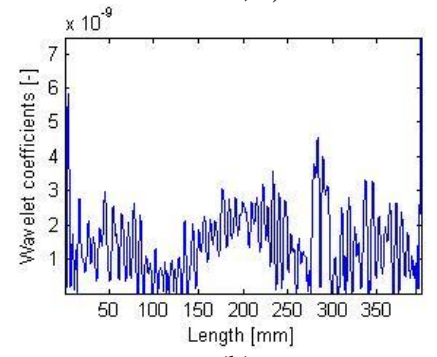

(b)

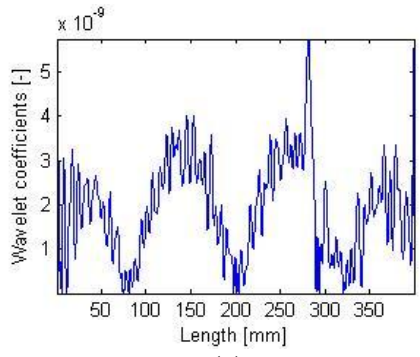

(c)

Fig. 9. Results of damage identification for damage scenario 3 obtained using SWT, for: a) first modal rotation; b) second modal rotation; c) third modal rotation

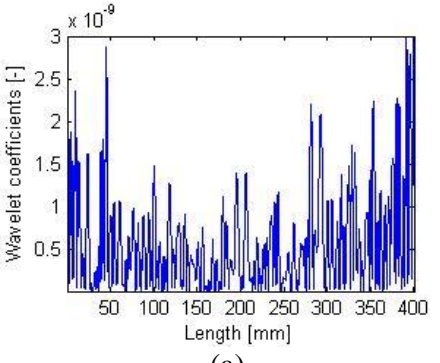

(a)

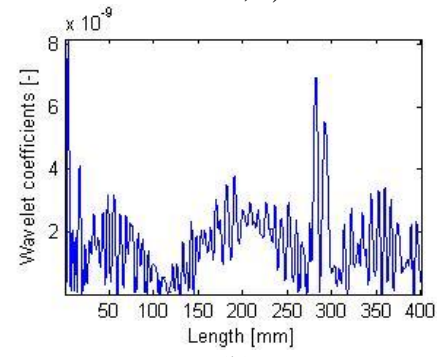

(b)

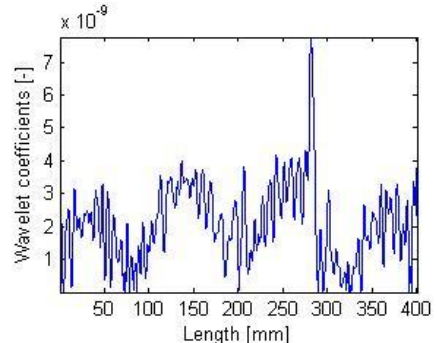

(c)

Fig. 10. Results of damage identification for damage scenario 8 obtained using SWT, for: a) first modal rotation; b) second modal rotation; c) third modal rotation

\section{FINAL REMARKS AND CONCLUSIONS}

The study on the application of various WTs with various wavelets showed a significant improvement in damage detectability with respect to the analysis of raw shearographic data. As reported in [6], the damage sites were not localized based on raw shearographic data. The CWT-based algorithm with $d b 2$ wavelet seems to be the most effective approach for structural damage identification, in view of the considered cases. The obtained results using the CWT-based algorithm reveal a similar damage detectability to the one using an optimal spatial sampling approach presented in [6].
It is worth to note that several important observations have been done during the performed analysis. Firstly, it was observed that the fourth mode shape was insensitive for all types of damage scenarios. This was caused by a coincidence of damage locations with the locations of nodes of mode shapes - with comparatively low magnitudes in these locations the identification of damage signatures is, theoretically, very difficult. Furthermore, in practice, i.e. in the case of experimental data, due to the presence of noise the detection and identification of damage in such conditions is extremely demanding, since the damage signatures magnitudes are covered by the magnitude of noise. Assuming that the location of 
damage is not known a priori, it is reasonable to combine results for different mode shapes to minimize the probability of coincidence of location of damage and a node of a mode shape. It was also observed that the excitation level has an influence on damage detectability. In general, the results for different excitation levels were similar, but in several cases a better detectability was achieved for lower excitation levels.

Further studies will be focused on the improvement of sensitivity of damage identification using wavelet-based algorithms as well as on the extension of the proposed approach to different damage types and different materials.

\section{REFERENCES}

1. Vogelesang LB, Vlot A. Development of fibre metal laminates for advanced aerospace structures. Journal of Materials Processing Technology 2000; 103(1): 15. https://doi.org/10.1016/S0924-0136(00)00411-8

2. Jardine AKS, Lin D, Banjevic D. A review on machinery diagnostics and prognostics implementing condition-based maintenance. Mechanical Systems and Signal Processing 2006; 20(7): 1483-1510. https://doi.org/10.1016/j.ymssp.2005.09.012

3. Márquez FPG, Tobias AM, Pérez JMP, Papaelias M. Condition monitoring of wind turbines: Techniques and methods. Renewable Energy 2012; 46: 169-178. https://doi.org/10.1016/j.renene.2012.03.003

4. Leendertz JA, Butters JN. An image-shearing speckle-pattern interferometer for measuring bending moments. Journal of Physics E: Scientific Instruments 1973; 6(11): 1107-1110. https://doi.org/10.1088/0022-3735/6/11/019

5. Hung YY, Taylor CE. Speckle shearing interferometric camera - a tool for measurement of derivatives of surface displacements. Proc. SPIE 1974; 41, Developments in Laser Technology II, 169177. https://doi.org/10.1117/12.953850

6. Mininni M, Gabriele S, Lopes H, Araújo dos Santos JV. Damage identification in beams using speckle shearography and an optimal spatial sampling. Mechanical Systems and Signal Processing 2016; 79: 47-64. https://doi.org/10.1016/j.ymssp.2016.02.039

7. Steinchen W, Yang LX, Kupfer G, Mäckel P, Vössig F. Strain analysis by means of digital shearography: Potential, limitations and demonstration. Journal of Strain Analysis for Engineering Design 1998; 33(2): 171-182. https://doi.org/10.1243/0309324981512896

8. Yang LX, Hung YY. Digital shearography for nondestructive testing: Potentials, limitations, and applications. Journal of Holography and Speckle 2004; 1(2): 69-79. https://doi.org/10.1166/jhs.2004.010

9. Hung YY. Digital shearography versus TVholography for non-destructive evaluation. Optics and Lasers in Engineering 1997; 26(4-5): 421-436. https://doi.org/10.1016/0143-8166(95)00141-7

10. Hung YY. Shearography: A novel and practical approach for nondestructive inspection. Journal of Nondestructive Evaluation 1989; 8(2): 55-67. https://doi.org/10.1007/BF00565631

11. Huang YH, Ng SP, Liu L, Chen YS, Hung YYM. Shearographic phase retrieval using one single specklegram: a clustering approach. Optical
Engineering 2008; 47(5): 054301.

https://doi.org/10.1117/1.2927462

12. Baaran J. Visual Inspection of Composite Structures. EASA-Research Project/2007/3. Final report. Institute of Composite Structures and Adaptive Systems, DLR Braunschweig, Braunschweig; 2009.

13. Kroworz A, Katunin A. Non-destructive testing of structures using optical and other methods: A review. Structural Durability \& Health Monitoring 2018; 12(1): 1-17. https://doi.org/10.3970/sdhm.2018.012.001

14. Reve GM, Pandarese G, Allevi G. Quantitative defect size estimation in shearography inspection by wavelet transform and shear correction. Proc. IEEE International Workshop on Metrology for AeroSpace (MetroAeroSpace), Padua, 2017; 535-540. https://doi.org/10.1109/MetroAeroSpace.2017.79996 $\underline{31}$

15. Katunin A, Lopes H, Araújo dos Santos JV. Identification of multiple damage using modal rotation obtained with shearography and undecimated wavelet transform. Mechanical Systems and Signal Processing 2019; 116: 725-740.

https://doi.org/10.1016/j.ymssp.2018.07.024

16. Araújo dos Santos JV, Lopes H. Damage localization based on modal response measured with shearography. In: Nobari AS, Aliabadi MHF, eds. Vibration-Based Techniques for Damage Detection and Localization in Engineering Structures. New Jersey, World Scientific, 2018; 141-172. https://doi.org/10.1142/9781786344977 0005

17. Katunin A. Diagnostics of composite structures using wavelets. Specialist Monographic Series "Library of Maintenance Problems" no. 2540. Radom: The Publishing House of the Institute for Sustainable Technologies - National Research Institute; 2015.

Received 2018-07-31

Accepted 2018-10-26

Available online 2018-10-29

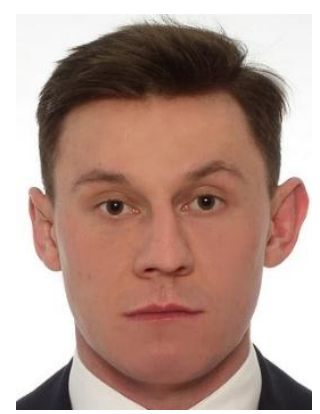

Aleksander KROWORZ received his BS degree in Materials Science, and MS degree in Machine Design and Operation with the speciality Lightweight Structures from the Silesian Technical University, Poland, in 2017, and 2018, respectively. His interests are focused on structural damage assessment, programming, aircraft design and engineering and electronics.

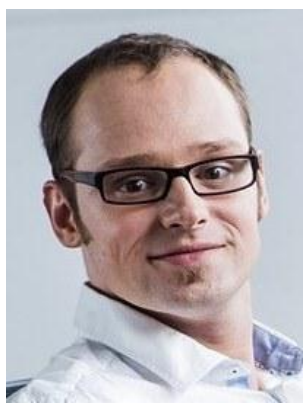

Andrzej KATUNIN received the BS degree in Mechanics from the Bialystok Technical University, Poland, in 2006, and his $\mathrm{MS}, \mathrm{PhD}$, and $\mathrm{DSc}$ degrees in Mechanics from the Silesian Technical University, Poland, in 2008, 2012, and 2015 , respectively. $\mathrm{He}$ is an associate professor on the research position in the Institute of Fundamentals of Machinery Design, Silesian University of Technology. His research 
interests include mechanics of composites with emphasis on fatigue and thermal effects, non-destructive testing methods, advanced signal and image processing techniques, wavelets and fractals theory and applications.

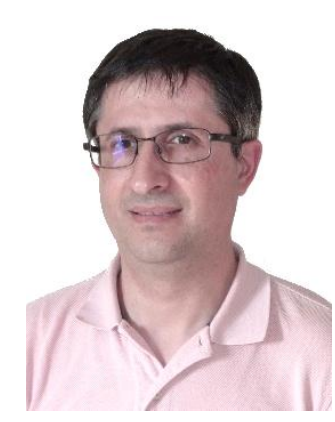

Hernâni LOPES received his BE in Mechanical Engineering from the Faculty of Engineering of the University of Porto, Portugal in 1997, his MS in Industrial Maintenance from the Faculty of Engineering of the University of Porto, Portugal in 2003 and his $\mathrm{PhD}$ in Mechanical Engineering from the Faculty of Engineering of the University of Porto, Portugal in 2008. $\mathrm{He}$ is an Assistant Professor in the Department of Mechanical Engineering at ISEP, Polytechnic of Porto and a Researcher at INEGI, both located in Porto, Portugal. His research interests are structural health monitoring and non-destructive testing using vibration analysis and techniques based on speckle interferometry.

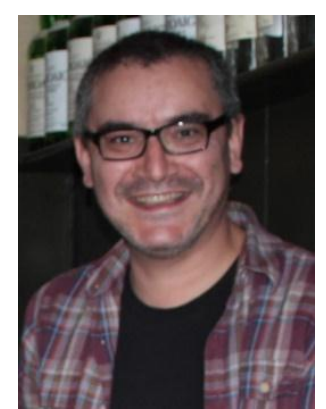

José ARAÚJO DOS SANTOS received his BE in Mechanical Engineering from the New University of Lisbon, Portugal in 1992 and his MS and PhD from the Technical University of Lisbon in 1996 and 2006, respectively. He is an Assistant Professor in the Department of Mechanical Engineering at Instituto Superior Técnico, Universidade de Lisboa and a Researcher at IDMEC, both located in Lisbon, Portugal. His research interests are structural health monitoring with emphasis on damage identification, nano and composite materials, and computational mechanics. 